\title{
PLZT-modified relaxor piezoelectric ceramic system for medical diagnostic applications
}

\author{
Koduri Ramam* and Marta Lopez \\ Departmento de Ingeniería de Materiales (DIMAT), Facultad de Ingeniería, Universidad de Concepción, \\ Edmundo Larenas 270, Casilla 160 C, Concepción, Chile
}

(Received 14 October 2007; final version received 10 June 2008)

\begin{abstract}
The piezoelectric ceramic system $\left[\mathrm{Pb}_{0.978-\mathrm{y}} \mathrm{La}_{0.012} \mathrm{Ba}_{0.01} \mathrm{Sr}_{\mathrm{y}}\right]\left[\left(\mathrm{Zr}_{0.534} \mathrm{Ti}_{0.466}\right)_{0.987} \mathrm{Nb}_{0.008}\right] \mathrm{O}_{3}$ (PLBSZNT) has been fabricated for use in medical diagnostics applications. The fundamental pre-requisites are high-density, high dielectric constant and high piezoelectric properties that serve as compatible ceramic materials for medical diagnostic applications. It is essential for sensitive transducers that the piezoelectric ceramics must efficiently convert between electrical and mechanical energy, and so the electromechanical coupling coefficients should be high, as the fabrication process of tiny elements for medical arrays must be carried out without damaging the material and its properties. In our study, Sr-modified PLBZNT had shown single ferroelectric tetragonal phase. An analysis of different Sr doping concentration is reported, and the high dielectric permittivity, low dielectric loss along with high electromechanical properties indicate that PLBSZNT is suitable for medical diagnostic applications as well as sensors and actuators.
\end{abstract}

Keywords: piezoelectric materials; dielectric permittivity; electromechanical properties; medical diagnostic applications.

\section{Introduction}

Piezoceramics based on lead zirconate titanate (PZT), well known for its outstanding electromechanical properties, are widely used for various potentially medical ultrasonic imaging/diagnostic applications (Gururaja 1994; Smith 1990). Piezoelectric composites with 1-3 connectivity (Newnham et al. 1978) have received a great deal of attention in medical imaging applications due to their similar properties to that of human tissues than other materials, and due to increased electromechanical coupling coefficients. There have been many fabrication structures developed for these applications, depending on the tailored properties, with several modifiers or substituents by different synthesis routes (Janas and Safari 1995; Lubitz 1993) both in bulk ceramic and thin film form.

In the past, fabricated material was used for suitable device-oriented applications. The advances in the field of ferroelectric and piezoelectric device development resulted in a revolution and the beginning of a new direction, namely the tailoring of a material to a specific application desired. Accordingly, the advancement in the field of ferroelectric and piezoelectric device development led to tailoring of properties to an optimum extent for the specific application desired (Heartling 1983). Piezoelectric devices have recently been used successfully in a range of medical applications, including an artificial fertilisation system, a medical micro-pump, micro-monitoring and surgery devices and drug delivery devices. Piezoelectric materials are suitable for medical applications since they produce no electromagnetic noise and are highly efficient. Piezoelectric materials having large electromechanical coupling coefficients, where $k_{\mathrm{t}}>0.4$ and $k_{\mathrm{p}}>0.6$ (characterising the electricalto-mechanical energy conversion efficiency), and high dielectric constant and piezoelectric charge coefficient $\left(d_{33}\right)$ with low dielectric loss $(\tan \delta<0.05)$ serve as compatible materials for ultrasonic applications (Koduri and Lopez 2007).

The objective of this study has therefore been to find an alternative or more stable material system which would not only offer the desired material characteristics for medical applications, but also allow a simple solid-state conventional processing route where highly predictable results can be obtained. Modified PLZT has been investigated since many decades and extensive work has been done on binary and ternary relaxor systems such as PMN-PZT (Hadjicostis et al. 1984), PZN-PLZT (Deng et al. 2006), PMNPLZT (Ramam and Lopez 2007) and modified PLZT (Ramam and Miguel 2006). The compositions synthesised have been represented in Table 1. The work in this investigation has been concentrated on the development of a solid solution herein named as PLBSZNT, which was found to be easier to process and at the same time could give maximum dielectric permittivity and high piezoelectric coupling coefficients with low dielectric loss. Furthermore, an in-depth exploration of the ferroelectric tetragonal phase region near the morphotrophic phase boundary (MPB) will

\footnotetext{
*Corresponding author. Email: ramamk@udec.cl
} 
Table 1. Sr-modified PLBZNT ceramic compositions.

\begin{tabular}{ll}
\hline General formula & {$\left[\mathrm{Pb}_{1-\mathrm{w}-\mathrm{x}-\mathrm{y}} \mathrm{La}_{\mathrm{w}} \mathrm{Ba}_{\mathrm{x}} \mathrm{Sr}_{\mathrm{y}}\right]\left[\left(\mathrm{Zr}_{\mathrm{z}} \mathrm{Ti}_{1-\mathrm{z}}\right)_{(1-(\mathrm{w} / 4)-(5 / 4) \mathrm{k})} \mathrm{Nb}_{\mathrm{k}}\right] \mathrm{O}_{3}$ (PLBSZNT) } \\
Chemical formula & {$\left[\mathrm{Pb}_{0.978-y} \mathrm{La}_{0.012} \mathrm{Ba}_{0.01} \mathrm{Sr}_{y}\right]\left[\left(\mathrm{Zr}_{0.534} \mathrm{Ti}_{0.466}\right)_{0.987} \mathrm{Nb}_{0.008}\right] \mathrm{O}_{3}$ (PLBSZNT) } \\
Mol\% & $\mathrm{La}=\mathrm{w}=1.2, \mathrm{Ba}=\mathrm{x}=1, \mathrm{Zr}=\mathrm{z}=53.4, \mathrm{Ti}=1-\mathrm{z}=46.6$, \\
& $\mathrm{Nb}=\mathrm{k}=0.8 \mathrm{~mol} \%, \mathrm{respectively.}$ \\
$y=0 \mathrm{~mol} \% \mathrm{Sr}$ & {$\left[\mathrm{Pb}_{0.978} \mathrm{La}_{0.012} \mathrm{Ba}_{0.01}\right]\left[\left(\mathrm{Zr}_{0.534} \mathrm{Ti}_{0.466}\right)_{0.987} \mathrm{Nb}_{0.008}\right] \mathrm{O}_{3}$} \\
$y=1 \mathrm{~mol} \% \mathrm{Sr}$ & {$\left[\mathrm{Pb}_{0.968} \mathrm{La}_{0.012} \mathrm{Ba}_{0.01} \mathrm{Sr}_{0.01}\right]\left[\left(\mathrm{Zr}_{0.534} \mathrm{Ti}_{0.466}\right)_{0.987} \mathrm{Nb}_{0.008}\right] \mathrm{O}_{3}$} \\
$y=2 \mathrm{~mol} \% \mathrm{Sr}$ & {$\left[\mathrm{Pb}_{0.958} \mathrm{La}_{0.012} \mathrm{Ba}_{0.01} \mathrm{Sr}_{0.02}\right]\left[\left(\mathrm{Zr}_{0.534} \mathrm{Ti}_{0.466}\right)_{0.987} \mathrm{Nb}_{0.008}\right] \mathrm{O}_{3}$} \\
$y=3 \mathrm{~mol} \% \mathrm{Sr}$ & {$\left[\mathrm{Pb}_{0.948} \mathrm{La}_{0.012} \mathrm{Ba}_{0.01} \mathrm{Sr}_{0.03}\right]\left[\left(\mathrm{Zr}_{0.534} \mathrm{Ti}_{0.466}\right)_{0.987} \mathrm{Nb}_{0.008}\right] \mathrm{O}_{3}$} \\
$y=4 \mathrm{~mol} \% \mathrm{Sr}$ & {$\left[\mathrm{Pb}_{0.938} \mathrm{La}_{0.012} \mathrm{Ba}_{0.01} \mathrm{Sr}_{0.04}\right]\left[\left(\mathrm{Zr}_{0.534} \mathrm{Ti}_{0.466}\right)_{0.987} \mathrm{Nb}_{0.008}\right] \mathrm{O}_{3}$} \\
\hline
\end{tabular}

provide an insight into the compositional dependence of the piezoelectric properties, hence $\mathrm{Zr} / \mathrm{Ti}=53.4 / 46.6$ has been chosen for this study. Emphasis is laid on the effect of $\mathrm{Sr}$ in the PLBZNT system and its effect on microstructure in turn influencing the dielectric and piezoelectric properties.

\section{Experimental procedure}

\subsection{Synthesis of materials}

PLBSZNT solid solutions were prepared by the solidstate reaction processing technique, starting with analytical reagent-grade powders (purity 99.99\%) of $\mathrm{PbO}, \mathrm{La}_{2} \mathrm{O}_{3}$, $\mathrm{BaCO}_{3}, \mathrm{SrCO}_{3}, \mathrm{ZrO}_{2}, \mathrm{TiO}_{2}$ and $\mathrm{Nb}_{2} \mathrm{O}_{5}$. The weighed starting reagents were mixed in appropriate stoichiometric ratios with the addition of excess $5 \mathrm{wt} \% \mathrm{PbO}$ to compensate lead loss during high-temperature sintering to form the final composition (abbreviated hereafter as PLBSZNT). The batch powders were ball-milled using zirconia balls and ethanol as media for $24 \mathrm{~h}$. The dried powders were calcined at $925^{\circ} \mathrm{C}$ for $4 \mathrm{~h}$ in a high-purity alumina crucible by maintaining air atmosphere. Calcined powders were ballmilled using zirconia balls and ethanol as media for $24 \mathrm{~h}$ to crush agglomerates and to minimise the particle size. The calcined fine powders were mixed with $5 \mathrm{wt} \%$ polyvinyl alcohol (PVA, as binder) and were compacted into diskshaped samples sizing $12 \mathrm{~mm}$ in diameter and 2-3 $\mathrm{mm}$ in thickness using steel die and hydraulic press under uniaxial pressure of $700-900 \mathrm{~kg} / \mathrm{cm}^{2}$. The binder was burnt off at $500^{\circ} \mathrm{C}$ for $3 \mathrm{~h}$ and sintered at $1225-1250^{\circ} \mathrm{C}$ for $4 \mathrm{~h}$ in a lead-rich environment and fired in closed alumina crucibles to minimise lead oxide volatilisation. After the sintering process, the samples were furnace-cooled to room temperature.

\subsection{Structural characterisation}

The sintered specimens were analysed by Philips X-ray diffractometer PW-1710 using $\mathrm{CuK}_{\alpha}$ radiation with Ni filter at room temperature and a step scan from $2 \theta=20^{\circ}$ to $60^{\circ}$. As-sintered ceramic surfaces were polished, thermally etched at $1045^{\circ} \mathrm{C}$ for $1 \mathrm{~h}$ and gold-coated (including fractured surfaces) using a sputtering technique to analyse microstructure. Microstructural studies were observed through scanning electron microscopy (SEM) of JEOL Model JSM 840A. The grain sizes and apparent densities of sintered ceramics were measured by the linear interception method with scanning electron micrographs and the Archimedes method, respectively. The particle size of the calcined powders was studied using a transmission electron microscope (JEOL JEM 1200).

\subsection{Dielectric and piezoelectric characterisation}

The lapped pellet surfaces were painted with silver paste and cured at $600^{\circ} \mathrm{C}$ for $1 \mathrm{~h}$ to form perfect electrodes on the sample surfaces and these specimens were characterised for room temperature dielectric constant $\left(\varepsilon_{\mathrm{RT}}\right)$, dielectric maximum $\left(\varepsilon_{\mathrm{Tc}}\right)$, Curie temperature $\left(T_{\mathrm{c}}\right)$ and dissipation factor $(\tan \delta$ ) at $1 \mathrm{kHz}$ using the 4192A HP Impedance Analyzer. In this study, the temperature change was provided by an automatic temperature chamber (Delta 2300) controlled by HP computer. The electroded specimens were poled in silicone oil bath at $100^{\circ} \mathrm{C}$ by applying a dc field $20 \mathrm{kV} / \mathrm{cm}$. After 24-h ageing, the poled specimens were characterised for the piezoelectric properties. The piezoelectric coefficients (planar coupling coefficient $\left(k_{p}\right)$ and thickness coupling coefficient $\left(k_{t}\right)$ ) of the poled samples were characterised by using the 4192A HP Impedance Analyzer through resonance and anti-resonance techniques. The piezoelectric charge coefficient $\left(d_{33}\right)$ was characterised by using a Berlincourt piezo-d-meter.

\section{Results and discussion}

\subsection{Phase and microstructure characterisation}

Figure 1 shows (a) X-ray diffraction patterns (XRD) of PLBSZNT ceramics, (b) Bragg angle $\left(43^{\circ}\right.$ to $\left.57^{\circ}\right)$ to indicate peak splitting (002) and (200), and (112) and (211) of $4 \mathrm{~mol} \% \mathrm{Sr}$, (c) Bragg angle $\left(43^{\circ}\right.$ to $\left.46^{\circ}\right)$ to indicate peak splitting (002) and (200), and (d) Bragg angle $\left(54^{\circ}\right.$ to $\left.56^{\circ}\right)$ to indicate peak splitting (112) and (211). XRD reveals a single-phase material with tetragonal structure. It is observed that as the $\mathrm{Sr}$ content increased, the tetragonality 

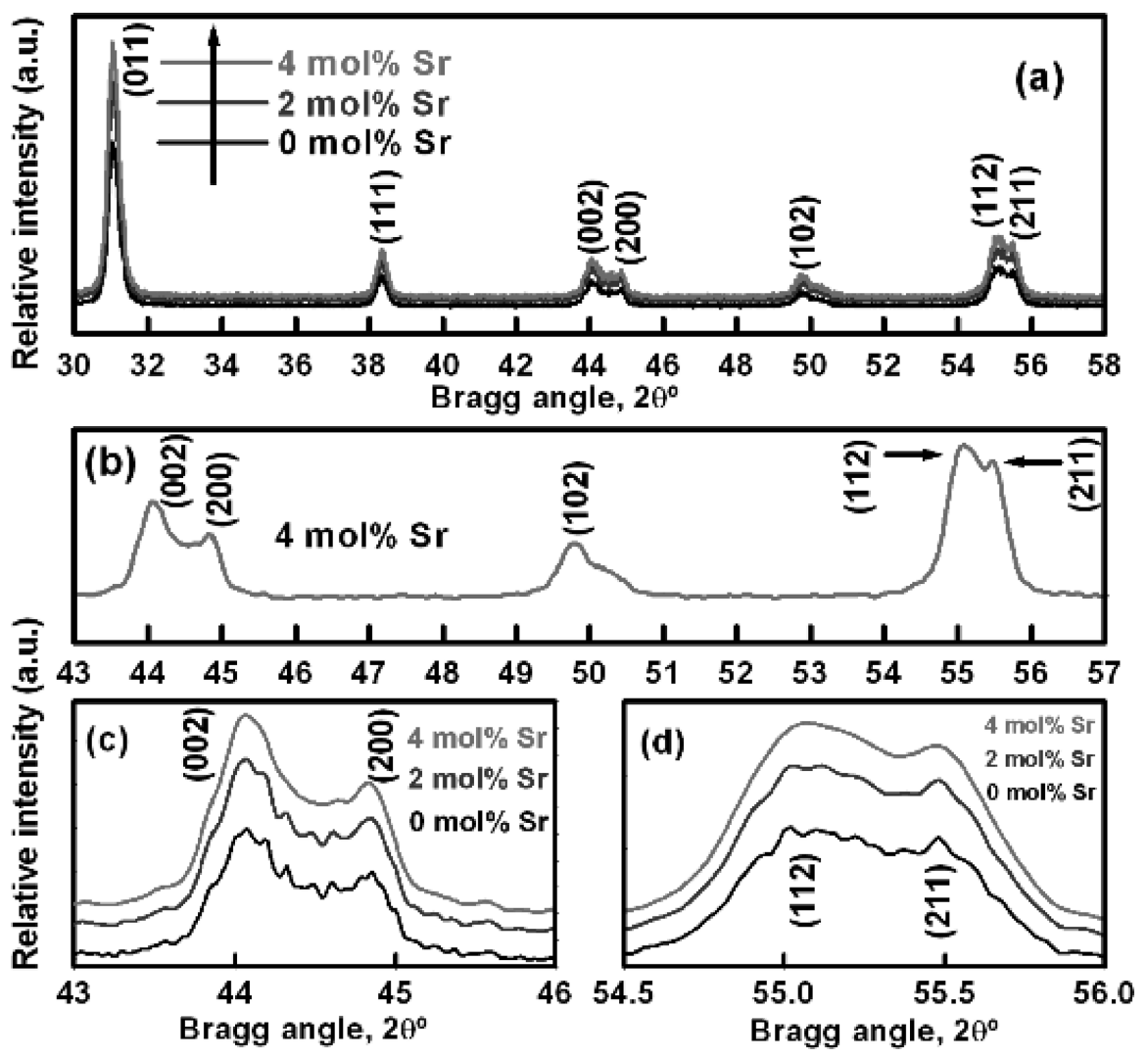

Figure 1(a-d). X-ray diffraction patterns of PLBSZNT ceramic system.

intensified when compared to the undoped composition. The zirconium $\left(\mathrm{PbZrO}_{3}\right)$-rich end is rhombohedral and the titanium $\left(\mathrm{PbTiO}_{3}\right)$-rich end is tetragonal, and the MPB separates these two regions. It is known that $(\mathrm{Pb}, \mathrm{La})(\mathrm{Ti}, \mathrm{Zr}) \mathrm{O}_{3}$ solid solutions with compositions on the tetragonal side near the MPB have excellent electrical properties. It is also known that at the MPB, the coercive field is minimal and the domain wall movement is the strongest. The phase formation depends on the composition dependence of intrinsic properties which is inherent to a single-phase. It is noticed that the tetragonal peaks intensified as the Sr content increased and no secondary phases were observed and showed homogeneous crystallisation in the end products, which is supported by the SEM. In a tetragonal phase (titanium-rich, $\mathrm{PbTiO}_{3}$ ) region of $\mathrm{PZT}$ ceramics, both $180^{\circ}$ and $90^{\circ}$ domain walls exist. Usually, $180^{\circ}$ domains are switched sufficiently by an external field and are stable in a poled crystal. In the case of tetragonal PZT ceramics, 50\% of the domains perpendicular to the applied field can be reoriented by poling and about $44 \%$ of them are maintained after removing the poling field.

Figure 2(a) represents grain size variation and Figure 2(b) represents the scanning electron micrograph of fractured surface of $4 \mathrm{~mol} \% \mathrm{Sr}$. Figure 2(c) represents the transmission electron micrograph of $4 \mathrm{~mol} \% \mathrm{Sr}$, which indicates that the size of powder particles is in the range of 42-74 $\mathrm{nm}$. The ceramics average grain sizes were determined directly from the SEM micrographs by using the linear interception method (Mendelson 1969). A characterisation of the microstructure as a function of Sr doping in PLBZNT was performed by SEM in order to determine the grain size variation. It can be evidenced from the SEM that it was a very fine-grained and pore-free structure wherein no foreign phase was present in the ceramics. The grain size increased up to $4 \mathrm{~mol} \%$, which has been compared to the dielectric and piezoelectric characteristics. The solidphase reaction of these ceramic compositions can be mainly attributed to the diffusion of the isovalent dopant $\mathrm{Sr}^{2+}$ partially substituting $\mathrm{Pb}^{2+}$ ions in PLBSZNT perovskite.

The apparent density profile showed an increasing behaviour as Sr content was increased in the PLBZNT ceramics. The increase in density could be attributed to the tetragonality and pore-free grain growth which helped in promoting the densification in PLBSZNT ceramics. The domain wall motion and movement enhanced the ionic polarisation, which in turn influenced the density. The volume diffusion, being the main mechanism, is enhanced by the creation of $\mathrm{Pb}$ vacancies and it is controlled by the number of vacancies caused by modifiers, thus promoting density. The increase in grain size could be attributed to the domain size increment during the sintering process. The process of domain switching starts with nucleation at varied points 


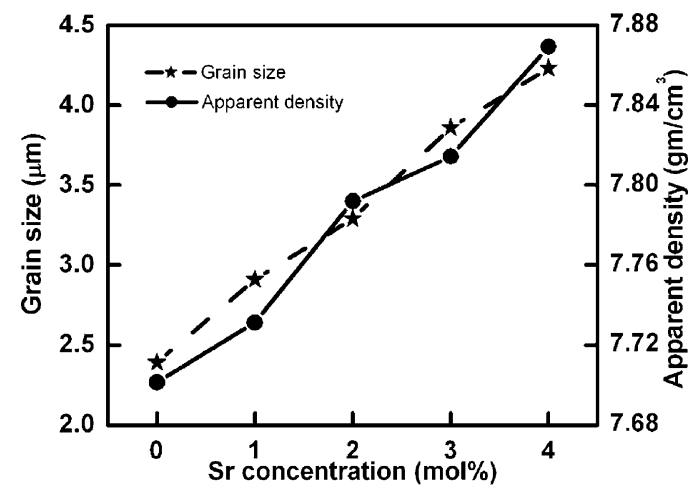

(a)

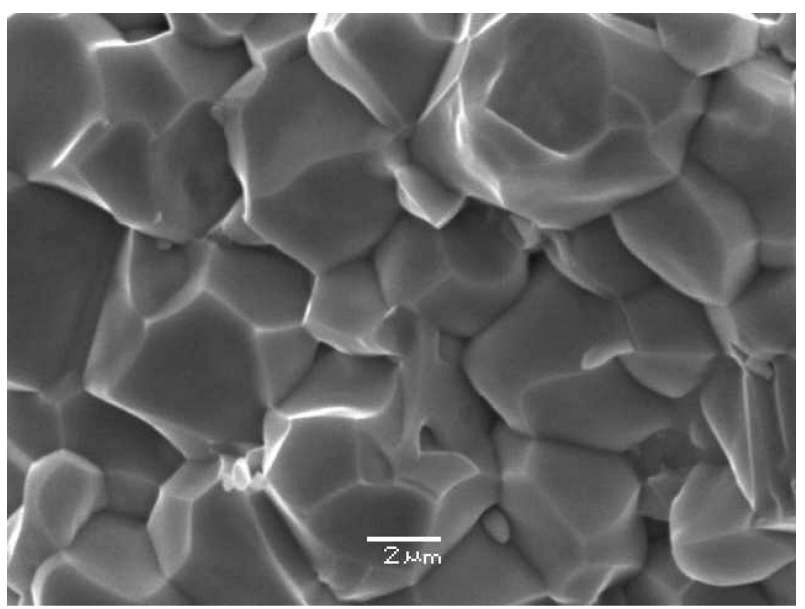

(b)

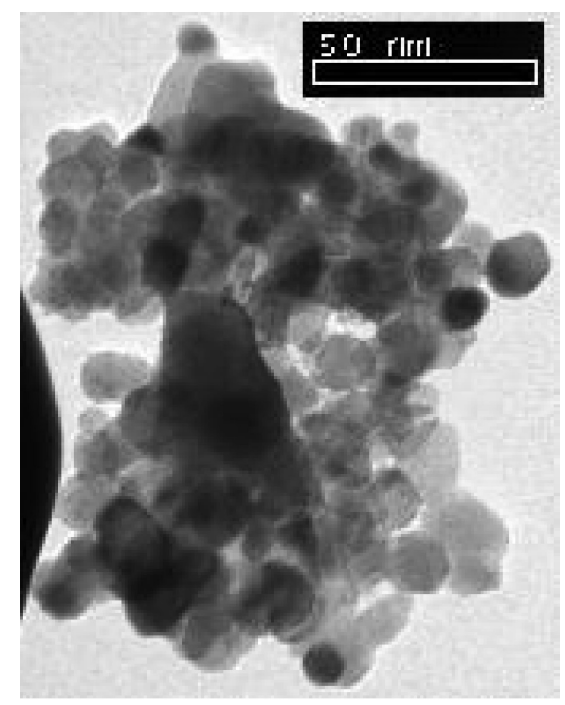

(c)

Figure 2. (a) Grain size and apparent density of PLBSZNT ceramic system; (b) scanning electron micrograph (fractured ceramic) of $4 \mathrm{~mol} \% \mathrm{Sr}$; (c) transmission electron micrograph of 4 $\mathrm{mol} \% \mathrm{Sr}$. on the domain followed by the switching of perovskite on the boundary of the domains, thus causing the spreading of the newly formed domain or the net resultant domain. The movement of this newly formed domain boundary is called domain wall movement. This domain wall movement is fully swept through the existing domains to complete the domain switching process and thus enhanced grain growth in PLBSZNT ceramics.

Accordingly, the net domain switching process from the existing multiple cations with intensified tetragonal symmetry had enhanced the net polarisation in the PLBSZNT ceramics. The grain size of a ceramic material is a critical microstructure feature because the domain size, domain structure and domain wall movement contribute to the polarisation thus resulting in enhanced electrical properties. In the tetragonal structure, the internal stains (or stresses) are gradually removed in the course of time by domain motion (by new domain nucleation, domain splitting and domain wall displacement). It is reported that the average grain size enhanced with the substitution of Sr in PZT (Banerjee et al. 2006) and Nb in PZT (Pan et al. 2005); accordingly the grain boundary between two enhanced grains will have relatively a large grain boundary. The grain size in piezoelectric materials depends on the ceramic composition and the sintering process.

\subsection{Dielectric behaviour}

Figures 3(a-d) show room temperature dielectric constant $\left(\varepsilon_{\mathrm{RT}}\right)$, dielectric loss $\left(\tan \delta_{\mathrm{RT}}\right)$, dielectric maximum $\left(\varepsilon_{\mathrm{Tc}}\right)$ and Curie temperature $\left(T_{\mathrm{c}}\right)$ of PLBSZNT ceramics at $1 \mathrm{kHz}$, respectively. The characterisation of the dielectric parameters as a function of dopant concentration was performed. The grain growth enhancement resulted in a high dielectric constant at the Curie point. In a single-ceramic system, the correlation between linear increment of granular growth influences increment of dielectric and piezoelectric properties. In the soft PZT ceramic materials, as polarisation increases within the domains, the domain wall movement influences dielectric behaviour. It is known that the domain wall existence and movement contribute considerably to the dielectric, piezoelectric and elastic properties of the PZT and PLZT ceramics (Celi et al. 2002; Ikeda 1959; Okazaki and Nagata 1973; Zhang et al. 1994).

The chemical formulae shown in Table 1 are based on the assumption that $\mathrm{Ba}^{2+}, \mathrm{La}^{3+}$ and $\mathrm{Sr}^{2+}$ partially substitute $\mathrm{Pb}^{2+}$ at the A-site of the perovskite and that vacancies are created in the B-site to achieve charge balance. The increment of the concentration of lead vacancies allowed the atomic diffusion process during the sintering, thereby achieving better compositional homogenisation resulting in dielectric constant increment. The multiple donor ions $\left(\mathrm{La}^{3+}, \mathrm{Sr}^{2+}\right.$ and $\left.\mathrm{Ba}^{2+}\right)$ partially substitute for $\mathrm{Pb}^{2+}$ (at A-site) and pentavalent $\mathrm{Nb}^{5+}$ partially substitutes for $\mathrm{Zr}^{4+} / \mathrm{Ti}^{4+}$ (at B-site), enhancing high dielectric constant 

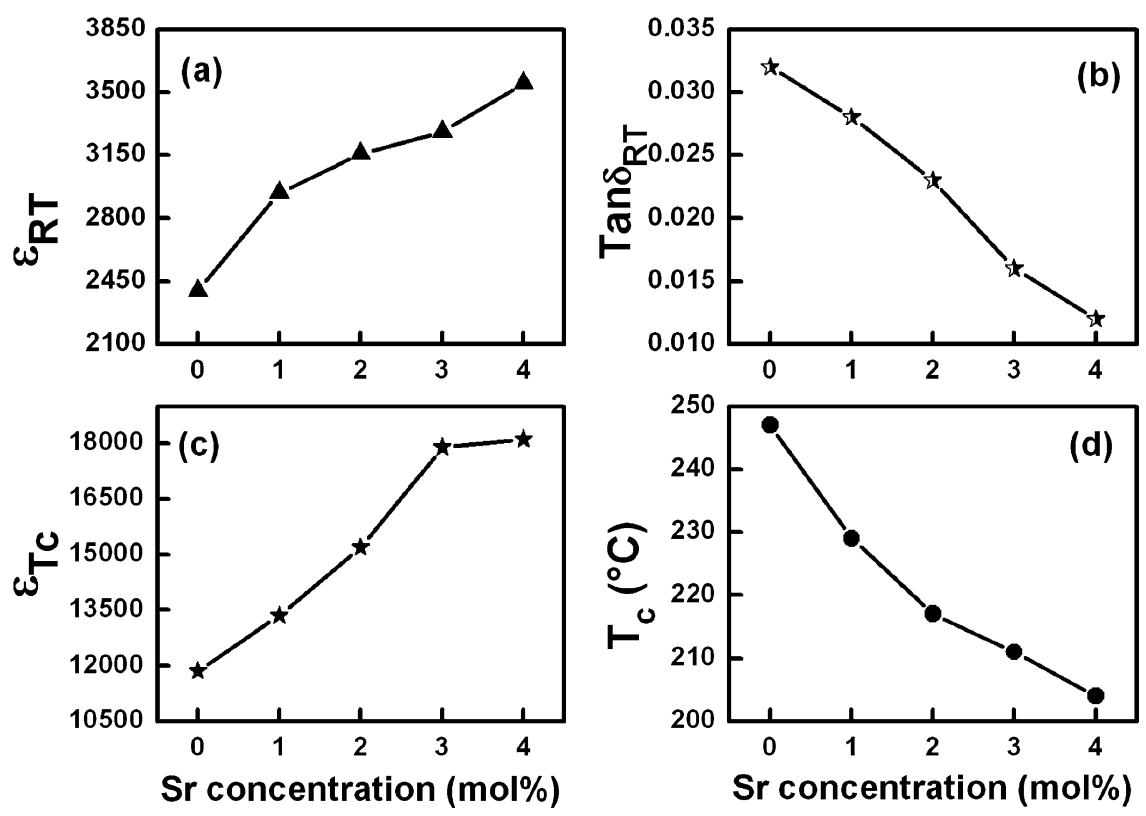

Figure 3(a-d). Dielectric behaviour of PLBSZNT ceramic system.

with a relatively decreasing Curie temperature and low dielectric loss at $1 \mathrm{kHz}$ till $4 \mathrm{~mol} \% \mathrm{Sr}\left(\varepsilon_{\mathrm{RT}}=3549\right.$ and tan $\delta=0.012$ ). In our study, dielectric constant $\varepsilon$ is calculated by using the formula (Shannon 1993; Smolensky 1970)

$$
\varepsilon=\frac{C d}{\varepsilon_{o} A}
$$

where $C$ is the capacitance of the ceramic, $d$ is the thickness of the ceramic, $A$ is the surface area of the ceramic and $\varepsilon_{o}$ is the permittivity of the free space $\left(8.85 \times 10^{-12} \mathrm{~F} / \mathrm{m}\right)$.

\subsection{Piezoelectric properties}

The piezoelectric planar coupling coefficient $\left(k_{p}\right)$ was characterised as follows: As per the IRE Standards on Piezoelectric Crystals: Measurements of Piezoelectric Ceramics (Mason and Van Nostrand 1950, 1958, 1961), the following formula has been employed to find out piezoelectric planar coupling coefficient $\left(k_{\mathrm{p}}\right)$ :

$$
\frac{k_{\mathrm{p}}^{2}}{1-k_{\mathrm{p}}^{2}}=2.51 \times\left[\frac{f_{\mathrm{a}}-f_{\mathrm{r}}}{f_{\mathrm{r}}}\right]
$$

where $k_{\mathrm{p}}$ is the piezoelectric planar coupling coefficient, $f_{\mathrm{r}}$ is the resonance frequency and $f_{\mathrm{a}}$ is the anti-resonance frequency of the poled ceramic. The resonance and antiresonance frequencies were measured by using the 4192A HP Impedance Analyzer.

Figure 4(a) depicts piezoelectric charge coefficient $\left(d_{33}\right)$ and Figure 4(b) shows piezoelectric planar coupling coef-

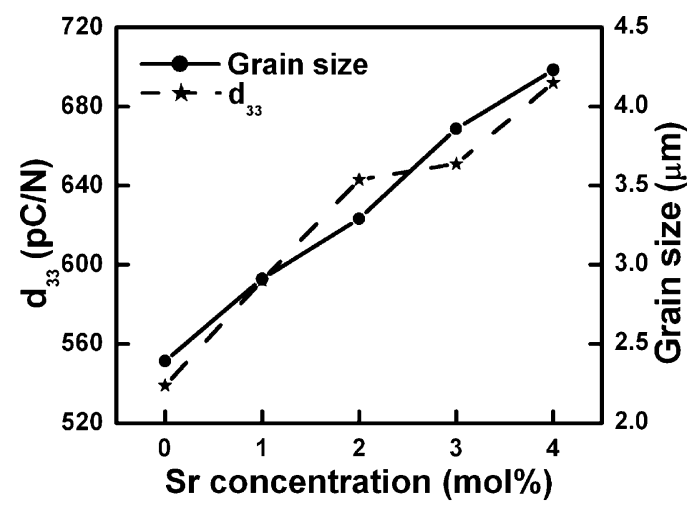

(a)

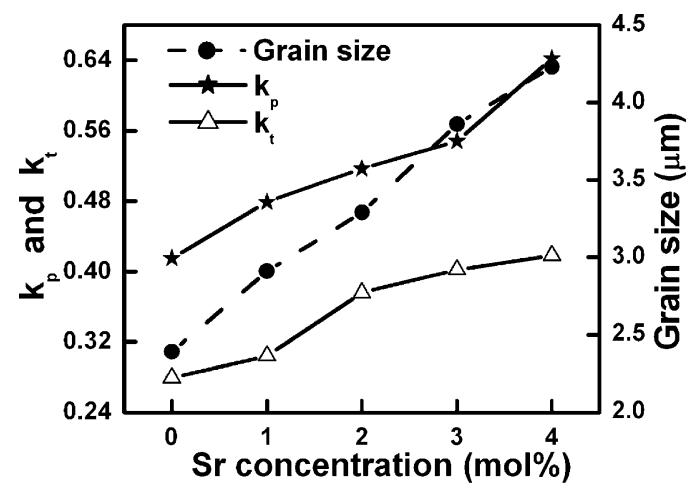

(b)

Figure 4(a). Variation of $d_{33}$ with Sr concentration of PLBZNT ceramic system; (b) variation of $k_{\mathrm{p}}$ and $k_{\mathrm{t}}$ with $\mathrm{Sr}$ concentration of PLBZNT ceramic system. 
ficient $\left(k_{\mathrm{p}}\right)$ and piezoelectric thickness coupling coefficient $\left(k_{\mathrm{t}}\right)$ of PLBSZNT ceramics. Figure 4(a) and (b) depicts the influence of grain size on piezoelectric properties of PLBSZNT ceramics. The fundamental difference in the way grains are gathered before and after the sintering process is that in the former grains are only physically bound together, but in the latter grains are bound by grain boundaries. Generally during the sintering process, as the temperature increases the atomic diffusion at elevated temperature, the area between grains in contact increases due to thermal expansion of the grains. As grain size increases, the net polarisation within the grain increases. As a result the ceramics show an electrical response due to a mechanical excitation and a mechanical response due to an electrical excitation. Thus, grain size influences piezoelectric properties. In general, piezoelectric properties of ceramics increase approximately linearly with increasing grain size. In fact, several parameters influence the properties of piezoelectric ceramics such as porosity, grain size, homogeneity and doping concentrations (soft/hard) (Ramam et al. 2007). The increasing grain size enhanced the piezoelectric properties until $4 \mathrm{~mol} \% \mathrm{Sr}\left(k_{\mathrm{p}}=0.642, k_{\mathrm{t}}=0.418\right.$ and $d_{33}=$ $692 \mathrm{pC} / \mathrm{N})$.

A number of materials have recently been developed specifically for advanced ultrasound applications. The fundamental pre-requisites of ceramic materials are highdensity, high dielectric constant and high piezoelectric properties for transducers, sensors and actuators applicable for medical diagnostics. The enhancement in the properties results in the materials that range from greater strength and improved machinability to increased transducer element capacitance and coupling coefficients. There are several requirements for the piezomaterial to be used for transducers, sensors and actuators for medical diagnostic applications. It is essential for sensitive transducers that the piezoelectric must efficiently convert between electrical and mechanical energy, and so the electromechanical coupling coefficients should be high. The high electromechanical coupling coefficients help during transmission and reception. The dielectric constant must be high because the electrical impedance should be compatible with the driving and receiving electronics. Finally, good sensitivity and low loss also help the material to be suitable for medical diagnostic applications.

It is reported in the literature (Ikeda 1959) that with increasing concentration of modifiers after attaining saturation, there is a decrease in the piezoelectric properties. It is observed in the literature that co-doping ceramics with strontium $(x=0.06)$ and barium $(y=0.06)$ resulted in the disappearance of the $1 / 2 \mathrm{hkl}$ reflections while exclusively $\mathrm{Sr}-$ doped PZT solubility limit is $16 \mathrm{~mol} \%$ (Zheng et al. 2002). It is also observed that as isovalent $\mathrm{Sr}$ content increased, the $d_{33}$ values decreased (Zheng et al. 2002). Furthermore, the piezoelectric values decreased as isovalent $\mathrm{Ba}$ content increased, as reported in our previous publication (Ramam and Lopez 2007). Previous investigations in literature state that to avoid the degeneration of properties, the amount of Sr substitution in PZT must be less than 10 at\% (Xu 1991). Thus, we have chosen $\mathrm{Sr}$ dopant concentration till $4 \mathrm{~mol} \%$ which is the optimum solubility limit as per literature.

Our results for $4 \mathrm{~mol} \%$ PLBSZNT conform to the prerequisites with a high dielectric permittivity, high piezoelectric properties, low dielectric loss. Hence, it can be concluded that this composition could be compatible for bio-medical applications (Bove et al. 2001; Eremkin et al. 2004; Kutnjak et al. 2006; Ramam and Lopez, 2007; Yamashita et al. 1998; Zhang et al. 2004).

\section{Conclusion}

This work has systematically studied the PLZT with several (hard) acceptor and/or donor (soft), isovalent dopants along with different $\mathrm{Zr}$ /Ti ratios near morphotrophic phase boundary for specific applications desired. This work has demonstrated the development of a piezoelectric ceramic material in Sr-modified PLBZNT, optimised for medical diagnostic applications. The composition of this material was selected from the optimised composition of our previous study, which gave high dielectric permittivity, high piezoelectric properties and low dielectric loss in comparison with undoped conventional PLZT-based compositions. In this study, our results are in confirmation with that of the pre-requisites for medical diagnostic applications. The size of powder particles was in the range of $42-74 \mathrm{~nm}$. The microstructural studies reveal that the compositions were homogeneous and the domain wall mobility due to multiple ions had resulted in the enhanced grain growth. Microstructural studies revealed that increased grain growth had influenced the dielectric and piezoelectric properties in Sr-modified PLBZNT ceramic system. It has been observed that there is a remarkable influence on the dielectric and piezoelectric parameters wherein high $\varepsilon_{\mathrm{RT}}(3549), k_{\mathrm{p}}$ $(0.642), k_{\mathrm{t}}(0.418)$ and $d_{33}(692 \mathrm{pC} / \mathrm{N})$ values with low $\tan \delta$ $(0.012)$ have been achieved in $4 \mathrm{~mol} \%$ PLBSZNT ceramic system. Thus, 4 mol\% PLBSZNT could be the optimum composition compatible for the medical diagnostic applications.

\section{Acknowledgments}

The authors thank Direction of Investigation, University of Concepcion, for the financial assistance extended. The authors would also like to thank and acknowledge Jornadas Chilenas de Ingenieria Biomedica, Viña del Mar, Chile, and Mr. Ranganathan, Mr. Krishnamurthy and Ms. C. Neeladevi for their technical assistance and valuable suggestions provided during this work.

\section{References}

Banerjee A, Bandyopadhyay A, Bose S. 2006. Influence of $\mathrm{La}_{2} \mathrm{O}_{3}$, $\mathrm{SrO}$, and $\mathrm{ZnO}$ addition on PZT. J Am Ceram Soc. 89:15941600 . 
Bove T, Wolny W, Ringgaard E, et al. 2001. New piezoceramic PZT-PNN material for medical diagnostics applications. J Euro Ceram Soc. 21:1469-1472.

Celi LA, Caballero AC, Villegas M, et al. 2002. Effect of grain growth control on PZT properties. Ferroelectrics. 270:105110 .

Deng G, Ding A, Zheng X. 2006. Property improvement of $0.3 \mathrm{~Pb}\left(\mathrm{Zn}_{1 / 3} \mathrm{Nb}_{2 / 3}\right) \mathrm{O}_{3-} 0.7 \mathrm{~Pb}_{0.96} \mathrm{La}_{0.04}\left(\mathrm{Zr}_{\mathrm{x}} \mathrm{Ti}_{1-\mathrm{x}}\right)_{0.99} \mathrm{O}_{3}$ ceramics by hot-pressing. J Euro Ceram Soc. 26(12):2349-2355.

Eremkin VV, Smotrakov VG, Aleshin VA, et al. 2004. Microstructure of porous piezoceramics for medical diagnostics. Inorg Mater. 40(7):775-779.

Gururaja TR. 1994. Piezoelectrics for medical ultrasonic imaging. Am Ceram Soc Bull. 73:50-55.

Hadjicostis AN, Hottinger CF, Rosen JJ, et al. 1984. Ultrasonic transducer materials for medical applications. Ferroelectrics, 60(1-4):107-126.

Heartling GH. 1983. Piezoelectric and electrooptic ceramics. In Buchanan RC., ed. Ceramic Materials for Electronics, New York: Marcel Dekker Inc.

Ikeda T. 1959. Studies on $(\mathrm{Ba}-\mathrm{Pb})(\mathrm{Ti}-\mathrm{Zr}) \mathrm{O}_{3}$ system. J Phys Soc Jpn. 14(2):168-174.

Janas VF, Safari A. 1995. Overview of fine-scale piezoelectric ceramic/polymer composite processing. J Am Ceram Soc. 78:2945-2955.

Koduri R, Lopez M. 2007. Piezoelectric properties of Ag modified PMN-PZT solid solutions. Eur Phys J Appl Phys. 37:93-99.

Kutnjak Z, Petzelt J, Blinc R. 2006. The giant electromechanical response in ferroelectric relaxors as a critical phenomenon. Nature. 441:956-959.

Lubitz K, Wolff A, Preu G. 1993. Microstructuring technology. In Proceedings of the 1993 IEEE Ultrasonics Symposium, Institute of Electrical and Electronic Engineers. Piscataway, NJ. 515-524.

Mason W, Van Nostrand D. 1950, 1958, 1961. Piezoelectric crystals and their applications to ultrasonics. IRE standards on piezoelectric crystals: The electromechanical coupling factor. Proc. IRE, 46:764; IRE standards on Piezoelectric Crystals: Measurements of Piezoelectric Ceramics. Proc. IRE, 49:1161.

Mendelson MI. 1969. Average grain size in polycrystalline ceramics. J Am Ceram Soc. 52:443-446.

Newnham RE, Skinner DP, Cross LE. 1978. Connectivity and piezoelectric-pyroelectric composites. Mat Res Bull. 13:525536.
Okazaki K, Nagata K. 1973. Effects of grain size and porosity on electrical and optical properties of PLZT ceramics. J Am Ceram Soc. 56:82-86.

Pan MJ, Rayne RJ, Bender BA. 2005. Dielectric properties of Niobium and Lanthanum doped lead barium zirconate titanate relaxor ferroelectrics. J Electroceramics. 14:139148.

Ramam K, Lopez M. 2007. Barium modified lead lanthanum strontium zirconium niobium titanate for dielectric and piezoelectric properties. J Euro Ceram Soc. 27:3141-3147.

Ramam K, Lopez M. 2007. Dielectric, ferroelectric and piezoelectric studies of neodymium modified PLZNT ceramics for sensor and actuator applications. J. Alloys and Compounds, doi:10.1016/j.jallcom.2007.11.055.

Ramam K, Lopez M. 2007. Dielectric, ferroelectric and piezoelectric studies of PMN modified PLZT ceramics. Ferroelectric Letters, 34:95-107.

Ramam K, Miguel V. 2006. Microstructure, dielectric and ferroelectric characterization of Ba doped PLZT ceramics. Eur Phys J Appl Phys. 35:43-47.

Shannon RD. 1993. Dielectric polarizabilities of ions in oxides and fluorides. J Appl Phys. 73(1):348-366.

Smith WA. 1990. The Application of 1-3 piezocomposites in acoustic transducers. In Proceedings of the 7th International Symposium on Applications of Ferroelectrics. 145-152.

Smolensky GA. 1970. Proceedings of the 2nd International Meeting on Ferroelectricity, Kyoto, 1969. J Phys Soc Jpn. 28: 26.

$\mathrm{Xu}$ Y. 1991. Ferroelectric materials and their applications, Amsterdam: North-Holland, 101-160.

Yamashita Y, Harada K, Saitoh S, 1998. Recent applications of relaxor materials. Ferroelectrics. 219:29-36.

Zhang D, Su B, Button TW, et al. 2004. Piezoelectric 1-3 Composites for high frequency ultrasonic transducer applications. Ferroelectrics. 304:201-205.

Zhang QM, Wang H, Kim N, et al. 1994. Direct evaluation of domain-wall and intrinsic contributions to the dielectric and piezoelectric response and their temperature dependence on lead zirconate-titanate ceramics. J Appl Phys. 75(1): 454459.

Zheng H, Reaney IM, Lee WE, Jones N, Thomas H. 2002. Effects of octahedral tilting on the piezoelectric properties of Strontium/Barium/Niobium-Doped Soft Lead Zirconate Titanate Ceramics. J Am Ceram Soc. 85(9): 2337 2344. 

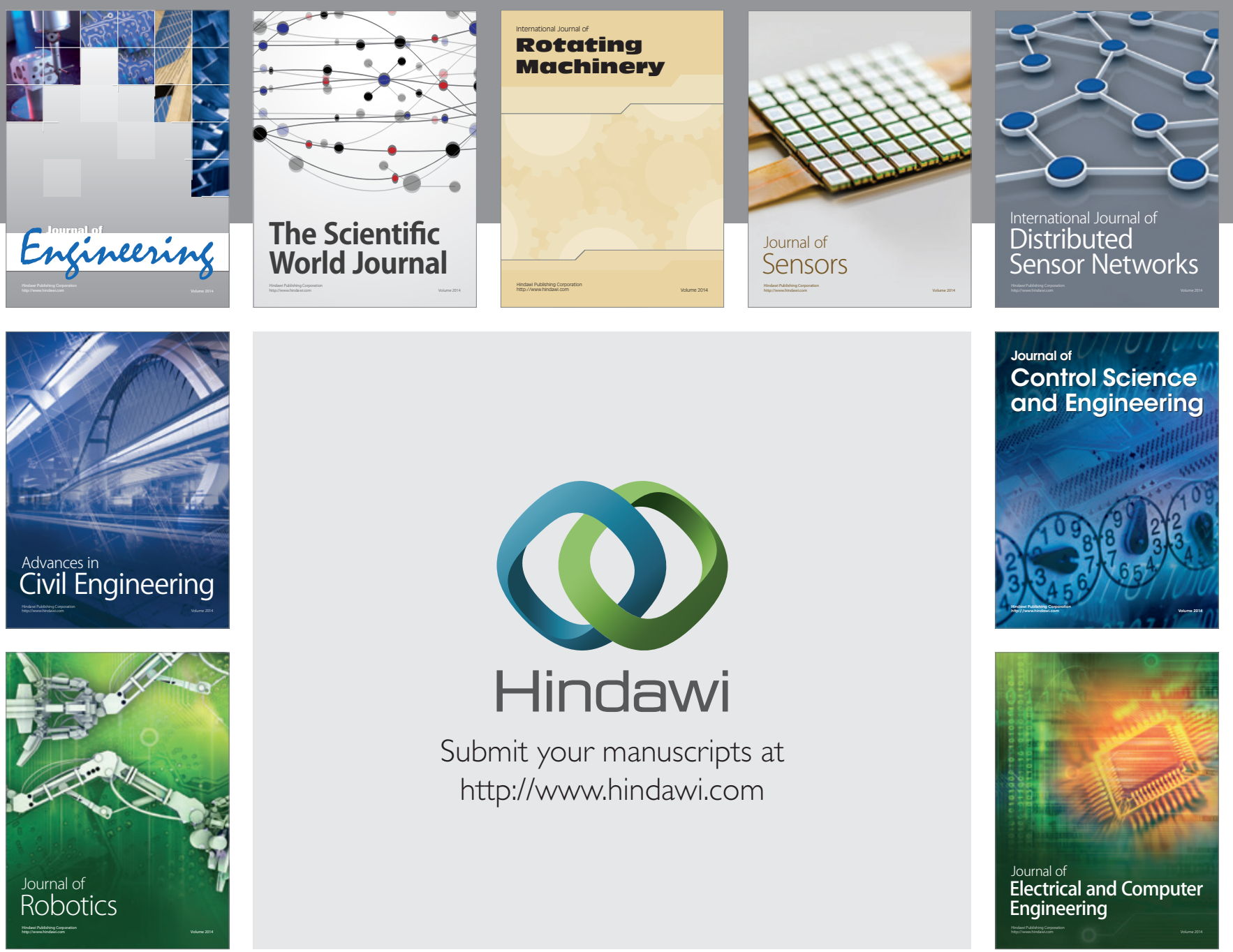

Submit your manuscripts at

http://www.hindawi.com
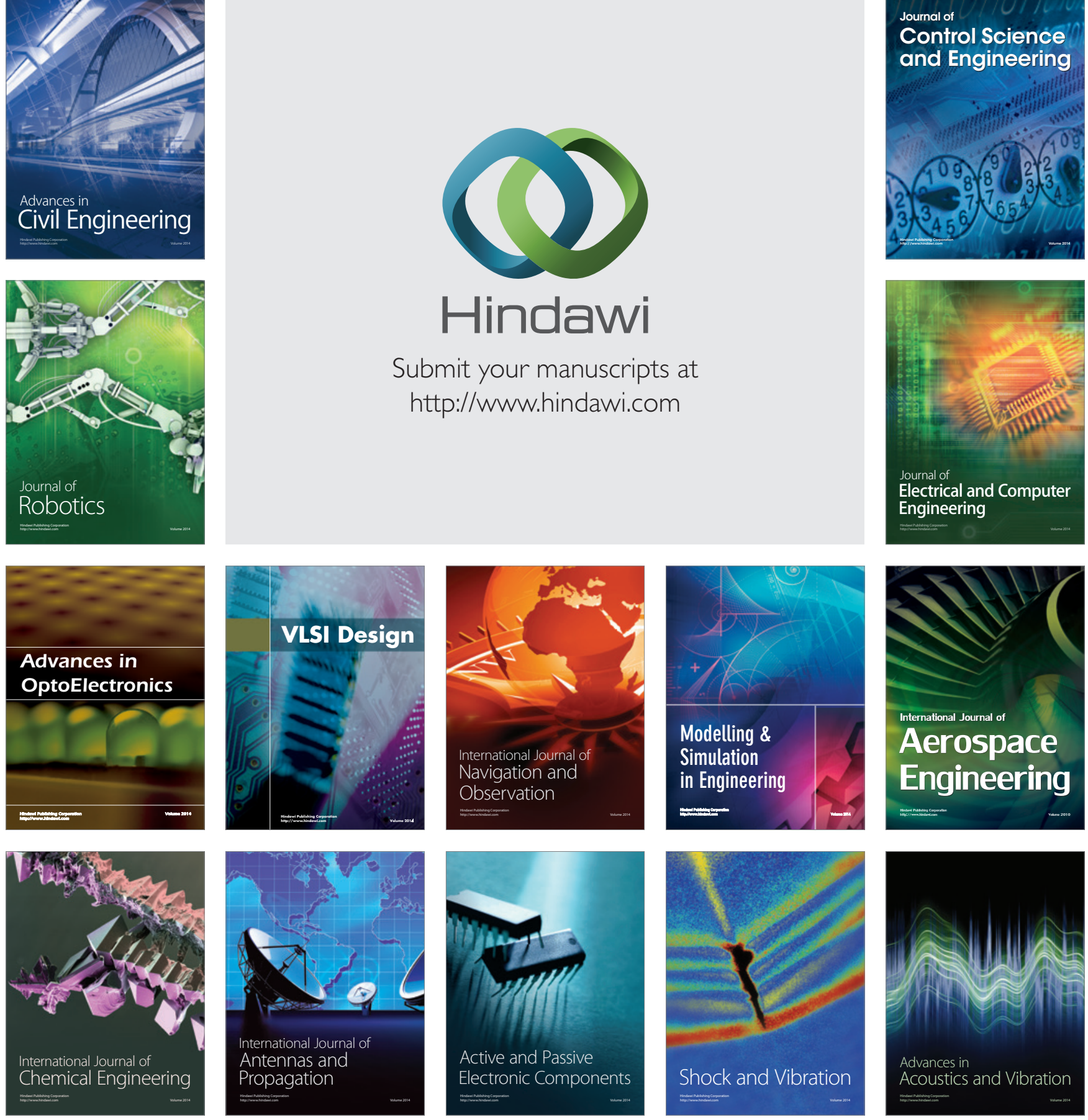